\title{
Eye and hand preference in rhesus monkeys
}

\section{(Macaca mulatta)'}

The extent of eye and hand preference and their correlation was tested, first in 19 naive, immature $S$ and then in seven experienced adolescent-to mature animals. There was no significant correlation between the two functions in either group. Hand preference, but not eye preference, was significantly greater in the older than in the younger monkeys.

A lack of correlation has been observed between eye and hand preference in the monkey, but the number of Ss studied was small and no statistical tests of the data were presented (Cole, 1957; Kounin, 1938). Kounin found 100 percent use of the right eye in three cebus monkeys and 99.5 percent use of the left eye in one rhesus. He reported that eye preference did not necessarily correspond with hand preference. More recently, Cole reported preferences ranging from 80 to 100 percent use of one eye in each of six nemestrina monkeys. He also indicated that there was no evidence that eyedness and handedness were related.

We wish to report the results from two experiments which more definitively pursued the question of correlation in eye and hand preferences.

\section{Method}

\section{EXPERIMENT I}

Our first study used 19 experimentally naive monkeys, ranging in weight from 2.5 to $3.4 \mathrm{~kg}$. Ss were tested in a modified Wisconsin General Test Apparatus (WGTA). Three tasks, each with two variations, were used for the hand preference measurements: (1) Simple reaching to take food from uncovered wells in the presentation tray, either (a) a centered well or (b) a randomly baited left or right well; (2) Taking food after moving a plain black wooden block from over either (a) a center well or (b) a randomly baited left or right well; (3) Taking food from a small metal cylinder ( $50 \mathrm{~mm}$ high by $30 \mathrm{~mm}$ diameter) attached to the end of a handle when (a) food was placed on the edge or (b) inside the cylinder (cup). The cup was presented in randomly varied positions (left, center, or right). Ten trials on each task variation were given daily for five sessions. On each trial the preferred hand was considered to be the one used to carry food to the mouth.

For the measure of eye preference, a piece of $10 \mathrm{~mm}$ diameter copper tubing was embedded in a clear plastic and cloth mesh screen. This unit was mounted in a piece of plywood and attached to the restraining bars in the front of the WGTA. With proper lighting the S's head could be seen when he sighted through the tube. Although all responses during six test sessions were tabulated, only monocular sightings were used in the analyses. In order to maintain $S$ interest, food was
DONALD C. KRUPER, BRUCE E. BOYLE AND R. A. PATTON

MONTEFIORE HOSPITAL AND UNIVERSITY OF PITTSBURGH

Table 1. Percent of responses with the preferred hand and eye; naive subjects

\begin{tabular}{lll} 
Subject & Hand & Eye \\
\hline$\# 198$ & $64.0 \mathrm{~L}$ & $97.6 \mathrm{~L}$ \\
$\# 199$ & $55.0 \mathrm{~L}^{*}$ & $89.7 \mathrm{~L}$ \\
$\# 201$ & $72.0 \mathrm{R}$ & $56.9 \mathrm{R}^{*}$ \\
$\# 202$ & $69.0 \mathrm{~L}$ & $82.1 \mathrm{~L}$ \\
$\# 204$ & $69.0 \mathrm{R}$ & $67.5 \mathrm{~L}$ \\
$\# 205$ & $77.6 \mathrm{~L}$ & $59.6 \mathrm{~L}$ \\
$\# 206$ & $73.3 \mathrm{R}$ & $64.1 \mathrm{~L}$ \\
$\# 207$ & $87.3 \mathrm{~L}$ & $81.4 \mathrm{~L}$ \\
$\# 208$ & $64.0 \mathrm{~L}$ & $68.8 \mathrm{R}$ \\
$\# 210$ & $75.6 \mathrm{~L}$ & $78.5 \mathrm{~L}$ \\
$\# 213$ & $85.0 \mathrm{R}$ & $79.3 \mathrm{~L}$ \\
$\# 216$ & $65.6 \mathrm{~L}$ & $89.7 \mathrm{~L}$ \\
$\# 219$ & $58.6 \mathrm{R}$ & $51.5 \mathrm{R}$ \\
$\# 226$ & $88.0 \mathrm{~L}$ & $91.0 \mathrm{R}$ \\
$\# 228$ & $51.3 \mathrm{~L} *$ & $66.7 \mathrm{R}$ \\
$\# 230$ & $90.6 \mathrm{~L}$ & $57.0 \mathrm{~L} *$ \\
$\# 231$ & $69.3 \mathrm{R}$ & $64.2 \mathrm{~L} *$ \\
$\# 232$ & $67.3 \mathrm{~L}$ & $66.4 \mathrm{~L}$ \\
$\# 234$ & $82.3 \mathrm{~L}$ & $54.8 \mathrm{R}^{*}$ \\
\hline
\end{tabular}

* Not significantly different from chance (.05 level)

pushed through the tube frequently. However, selective reinforcement of any given response was avoided by never putting food through immediately after a response.

Since a restraining bar passed vertically through the center of the front of the WGTA, the tube was extended inside, flush with the bar and $2.5 \mathrm{~cm}$ to the side. Eight Ss began with the tube left of center and 11 with it right of center, with sides reversed for the second half of 140 trials.

Results

The results (Table 1), indicated that 17 of the $19 \mathrm{Ss}$ showed a hand preference significantly greater than chance. ${ }^{2}$ Eleven of these were left handed. Fourteen of the 19 Ss showed a significant preference for one eye; ${ }^{2}$ in $11 \mathrm{Ss}$, the left. While more Ss preferred the left to the right eye and hand, the frequency of Ss with left preferences was not greater than might occur by chance. ${ }^{2}$ Furthermore, the correlation of left handedness and left eyedness was not significant ( $r h o=-.2042$, ns .05).

\section{EXPERIMENT II}

Method

The second experiment was performed with seven older monkeys, ranging in weight from 4.5 to $7.3 \mathrm{~kg}$, that had experience with various lever pressing tasks. Since the earlier experiments did not restrict the use of either hand, each $S$ had presumably used its preferred hand. Unfortunately, the specific data on this point are not available.

Handedness tests of the second experiment were done 
Table 2. Percent of responses with the preferred hand or eye; experienced subjects

\begin{tabular}{lcc} 
Subjects & Hand & Eye \\
\hline$\# 26$ & $99.0 \mathrm{~L}$ & $51.0 \mathrm{R} *$ \\
$\# 28$ & $91.0 \mathrm{R}$ & $82.0 \mathrm{R}$ \\
$\# 29$ & $99.0 \mathrm{R}$ & $74.0 \mathrm{R}$ \\
$\# 32$ & $97.0 \mathrm{R}$ & $68.0 \mathrm{~L}$ \\
$\# 40$ & $80.5 \mathrm{R}$ & $79.0 \mathrm{R}$ \\
$\# 48$ & $81.0 \mathrm{~L}$ & $83.0 \mathrm{~L}$ \\
$\# 193$ & $66.5 \mathrm{~L}$ & $77.0 \mathrm{~L}$ \\
\hline
\end{tabular}

* Not significantly different from chance (.05 level)

in a WGTA with only slight modifications from the procedures of the first. The use of food wells in the presentation trays (covered and uncovered) was identical for the tasks requiring those procedures. However, the cup test was replaced by one which used three clear glass jars of $80 \mathrm{~mm}$ height and $45 \mathrm{~mm}$ diameter that were attached to the top of the presentation tray, in a left, center, and right position. Only 10 trials were given with the jar test, so a total of 50 trials were given daily, for four days. Scores for the hand used to take food to the mouth were analyzed here, also.

For eyedness testing, an aluminum tube of $10 \mathrm{~mm}$ diameter was embedded in a piece of gray colored, rough textured Plexiglas that measured $25 \mathrm{~mm}$ by 75 $\mathrm{mm}$. These pieces were mounted on a plywood panel and the unit attached to the back opening of the WGTA. With the door raised and the lights properly adjusted, it was easy to identify the eye being used by a $S$ for sighting through the tube. As in the first experiment, food was pushed through the tube to maintain responding, but never immediately after the response.

Results

Table 2 shows the scores for hand and eye preferences for the second experiment. All seven monkeys had hand preference scores greater than chance, ${ }^{2}$ with four of these being over 90 percent. Eyedness showed relatively lower preferences, but the scores of six Ss were higher than chance. ${ }^{2}$ As in the first experiment, the correlation between left eye and left hand preference was not significant ( $\mathrm{rho}=+.4286$, ns .05). Additionally, the seven older Ss had a higher degree of hand preference than did the 19 younger animals (Mann-Whitney $U$, $\mathrm{p}<.01$ ).

\section{Discussion}

Two factors stand out from these experiments. First, the lack of a significant correlation between the use of a given hand and eye for either group confirms observations of both Kounin and Cole. The study of eye and hand preferences in humans also fails to indicate a significant correlation between the two functions (Fuller \& Thompson, 1960; Hécaen \& deAjuriaquerra, 1964; Merrell, 1957). Thus, it would seem that eye and hand preference are not mediated by a simple common factor, e.g. a single dominant hemisphere. In fact, the general concept of a dominant hemisphere in either monkey or man is misleading without additional specification of the task or function being studied. Second, a greater degree of handedness in the older Ss suggests the influence of variables acting through time, e.g. specific reinforcement for use of a given hand, effects of maturation, or others. This finding is consistent with the increase in handedness reported by Warren (1958) as the result of experiential variables. Interestingly, eye preference was not influenced in a similar way in these Ss, for higher percentage scores were not found for the older animals. ${ }^{3}$ Also, we are unaware of any experiential variables that would reasonably be expected to selectively reinforce the use of one eye in these monkeys.

The findings here are similar to results for humans and thus do not detract from the usefulness of the monkey as a model for the study of human brain function. However, in light of the increasingly clear differences in function of the cerebral hemispheres of man (Hecaen, 1962; Teuber, 1962; Weinstein, 1962), the usefulness of the model is limited by, among other things, a lack of demonstrated difference in the functions of the left versus the right hemispheres of the monkey. To show such differences in the monkey remains a challenging problem.

\section{References}

Cole, J. Laterality in the use of the hand, foot, and eye in monkeys. J. comp. physiol. Psychol., 1957, 50, 296-299.

Fuller, J. L., \& Thompson, W. R. Behavior genetics. New York: Wiley, 1960.

Hécaen, H. Clinical symptomatology in right and left hemispheric lesions. In V. B. Mountcastle (Ed.), Interhemispheric relations and cerebral dominance. Baltimore: Johns Hopkins, 1962. Pp. 215-243.

Hécaen, H., \& deAjuriaquerra, J. Left handedness: Manual superiority and cerebral dominance. New York: Grune \& Stratton, 1964.

Kounin, J. Laterality in monkeys. J. genet. Psychol., 1938, 52, 375-393.

Merrell, D. J. Dominance of eye and hand. Hum. Biol., 1957, 29, 314-328.

Teuber, H. Effects of brain wounds implicating right or left hemisphere in man. In V. B. Mountcastle (Ed.), Interhemispheric relations and cerebral dominance. Baltimore: Johns Hopkins, 1962. Pp. 131-158.

Warren, J. M. The development of paw preference in cats and monkeys. J. genet. Psychol., 1958, 93, 229-236.

Weinstein, $\mathbf{S}$. Differences in effects of brain wounds implicating right or left hemispheres. In V. B. Mountcastle (Ed.), Interhemispheric relations and cerebral dominance. Baltimore: Johns Hopkins, 1962. Pp. 159-176.

\section{Notes}

1. Supported by grants NB-01601-07 and K3-NB-16,610-03 from the Public Health Service of Dept. HEW. We thank Edward Krimmer for extensive technical assistance.

2. Difference from chance scores (at .05 level) were computed by using formula, $50 \% \pm 2 \sqrt{\mathrm{N}(\mathrm{p})(\mathrm{q})} \cdot-\frac{100}{\mathrm{~N}}$, with $\mathrm{N}$ equal all left or right responses, assuming $p$ of $p$ and $q$ each equal .50 .

3. Mann-Whitney $U, p>.10,2$-tailed. 